\title{
Renal Transplant in an Adult with Ellis Van Creveld Syndrome: A Case Report and Literature Review
}

\author{
Myftar Barbullushi $^{1^{*}}$, Alma Idrizi $^{1}$, Anila Laku$^{2}$, Eriola Likaj $^{1}$, Marsida Kasa $^{1}$, Nestor Thereska $^{1}$ \\ ${ }^{1}$ Service of Nephrology, UHC Mother Teresa, Tirana, Albania; ${ }^{2}$ Service of Biomolecular Genetic, UHC Mother Teresa, \\ Tirana, Albania
}

\begin{abstract}
Citation: Barbullushi M, Idrizi A, Laku A, Likaj E, Kasa M, Thereska N. Renal Transplant in an Adult with Ellis Van Creveld Syndrome: A Case Report and Literature Review. Maced J Med Sci. 2013 June 15; $6(2) \cdot 182-185$.

http://dx.doi.org/10.3889/MJMS.1857-5773.2013.0291.

Key words: chondroectodermal dysplasia; chronic renal failure; hemodialysis; postaxial polydactyly; renal transplantation.

"Correspondence: Myftar Barbullushi, Dibra Street, 372, Tirana, Albania, Tel: +355682045638. Fax: +35542363644. E-mail m_barbullushi@yahoo.com

Received: 23-Feb-2013; Revised: 18-Apr2013; Accepted: 21-May-2013; Online first: 29-May-2013

Copyright: (c) 2013 Barbullushi M. This is an open-access article distributed under the terms of the Creative Commons Attribution License, which permits unrestricted use, distribution, and reproduction in any medium, provided the original author and source are credited.

Competing Interests: The authors have declared that no competing interests exist.
\end{abstract}

\begin{abstract}
Ellis van Creveld syndrome (EVC) is a rare chrondro-ectodermal dysplasia. Renal abnormalities are found in few EVC cases with agenesis, dysplasia, megaureter and nephrocalcinosis. Rarely EVC syndrome is complicated with kidney failure and only one child required renal transplantation.

We report a patient who was diagnosed with EVC syndrome at birth. He developed hypertension at age 15 and gradually progressed to chronic kidney disease stage 5 requiring hemodialysis and
\end{abstract} renal transplantation.

\section{Introduction}

Ellis van Creveld syndrome (EVC) is a chrondro-ectodermal dysplasia described in 1940 by Richard Ellis and Simon van Creveld, inherited in an autosomal recessive manner with wide variable expression [1]. It is a relatively rare disorder but seems more common in the Amish population of United State of America and some Arab populations [2-4].

The EVC underlying gene was mapped to chromosome 4p16 [5] and mutations have been found in the EVC gene by Ruiz-Perez et al. [2]. Mutations in a second gene EVC2, which is arranged in a head to head configuration with the EVC gene on chromosome 4, have also been identified as causative of the disease in a number of patients [6]. Cardinal features of the syndrome are disproportionate small stature with increasing severity from the proximal to distal portions of the limbs, shortening of the middle and distal phalanges, polydactyly affecting hands usual bilateral, and occasionally, the feet and hydrotic ectodermal dysplasia mainly affecting the nails, hair and teeth.

Congenital cardiac defects, most commonly a defect of primary atrial septation producing a common atrium, occur in $60 \%$ of affected individuals [7-10]. The presence of congenital heart disease may support the diagnosis of the EVC syndrome and 
appears to be the main determinant of longevity. The oral manifestations spectrum is wide, including malocclusion, labiogingival adherences and gingival hypertrophy, labiogingival frenulum hypertrophy, enamel hypoplasia and hypodontia, etj. Several inconstant additional clinical findings are strabismus, epi- and hypospadias, cryptorchidism, and thoracic wall and pulmonary malformations. Renal abnormalities are found in rare cases with agenesis, dysplasia, megaureter and nephrocalcinosis. Cognitive and motor development is normal. Till now few cases of EVC syndrome complicated with kidney failure [11] are reported in literature and moreover only one case of childhood age is reported with renal transplantation in a patient with EVC syndrome [12].

We report a patient who was diagnosed with EVC syndrome at birth. He developed hypertension at age 15 and gradually progressive renal failure, requiring renal replacement therapy in 25 years old, initially hemodialysis and than a successful renal transplantation from his mother.

\section{Case report}

A 25-year-old man was admitted at our Service for end-stage renal disease (creatinine clearance $9 \mathrm{ml} / \mathrm{min}$, uremia $285 \mathrm{mg} / \mathrm{dl}$ and creatinine $12.5 \mathrm{mg} / \mathrm{dl})$, and arterial hypertension (190/120 $\mathrm{mmHg}$ ). On physical examination, the short stature of the patient was evident $(148 \mathrm{~cm})$ with disproportionate, narrow thorax, irregularly short extremities, short and wide hands (Figure 1), syndactyly of feet (Figure 2), genu valgum, dystrophic to friable nails, cutaneous syndactyly of second and third toes bilaterally.

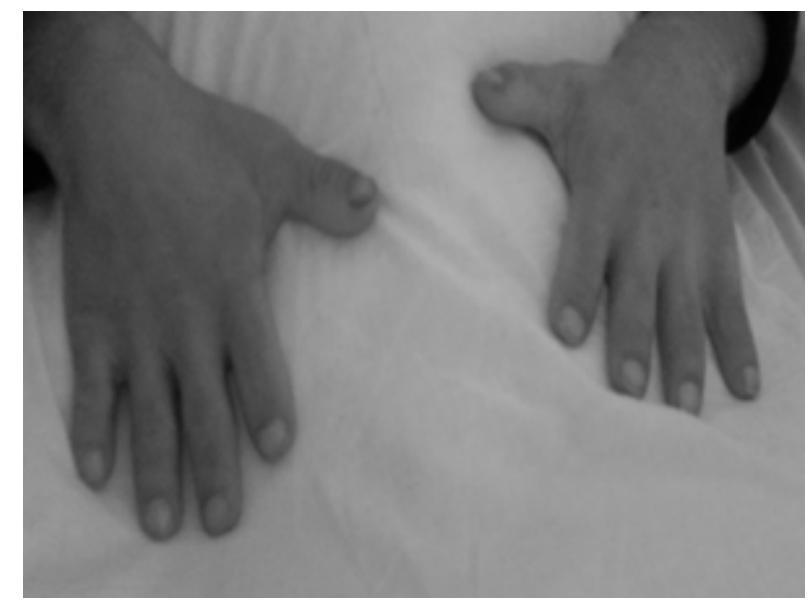

Figure 1: Hands anomalies (image after intervention).

The examination of the right hand and the left foot revealed the scars because of the surgical excision of the extra fingers before the first year of life. $\mathrm{He}$ also had short upper lip bound by frenula to alveolar ridge and dental abnormalities; partial anodontia, small teeth, enamel hypoplasia, gingival abnormalities in the level of inferior incisives. In cardiac auscultation a systolic cardiac murmur was noted. Echocardiography revealed a mild tricuspidal regurgitation. There were small cysts at the corticomedullary junction on kidneys' ultrasound, supporting the diagnosis of nephronophtisis.

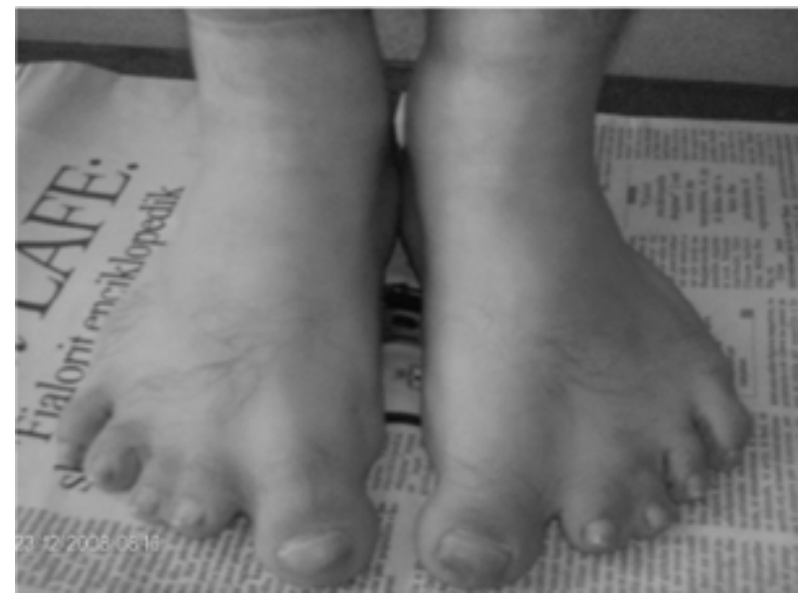

Figure 2: Feet anomalies, including syndactyly.

The patient was the fourth child of healthy non-consanguineous parents. In the family history, the two patient's brothers diagnosed only clinically for EVC syndrome died in early infancy as a consequence of cardiorespiratory problems. The first child was a normal girl. The second child who lived only 4 months had polysyndactylia in both hands and feet. The autoptic findings showed biliary tract atresia and a defect of primary atrial septation with a single atrium. The third male child, hypotrophic had polydactylia in both hands and one foot and undeveloped genital organs. He lived only 5 hours. As regard our patient, he was born at term; birth weight was 2400 grams, length $46 \mathrm{~cm}$, head circumference $34 \mathrm{~cm}$ and thoracic circumference $27 \mathrm{~cm}$. Early after birth, he was referred to the service of medical genetics. The patient presented disproportionate short stature with acromelic and mesomelic shortness of the limbs and postaxial polydactyly of the right hand and the left foot. He showed also labiogingival frenulum hypertrophy and narrow thorax. No genital anomalies were found. At three years old the patient was diagnosed only clinically for EVC syndrome. At that age, he presented dysplastic nails and teeth. His psychomotor and mental development was within normal limits. Radiographic examination confirmed retarded bone maturation, shortening of the limb bones with abnormally shaped metaphyses, hypoplasia of the medial and distal phalanges, and dysplasia of the pelvis. The routinely check-up it was neglected after the three first years of life. The patient developed hypertension at age 15 and gradually progressive renal failure, requiring renal replacement therapy in 25 years old, initially hemodialysis for three months and than a successful renal transplant from his mother. 


\section{Discussion}

The present case and his family history correspond to a rare form of EVC syndrome, with an extend clinical spectrum, with different organ involvement and outcomes within a family. The brothers of our patient died from cardiorespiratory failure, while our patient developed renal failure in an adult age with a successful renal transplantation from his mother.

EVC syndrome is generally non-lethal with approximately two-thirds of those affected surviving to adulthood. Mortality is higher when the congenital heart defects associated with EVC syndrome are also present. Approximately half of those affected with EVC syndrome with heart abnormalities die in childhood as a consequence of cardiorespiratory problems.

Also EVC and Jeune's asphyxiating thoracic dystrophy (ATD) are disorders characterized by narrow thoracic cage and short-limbed dwarfism. Some patients have overlapping features of both ATD and EVC, but polydactyly is an inconstant feature of ATD and nail dysplasia and peculiar upper lip are not seen in this condition. Individuals with Jeune syndrome often die of respiratory distress shortly after birth, whereas individuals diagnosed with EVC syndrome are more likely to die from congenital heart failure. Nephronophthisis has been occasionally reported in patients with ATD, and rarely in patients with EVC syndrome [12]. Only few cases are reported in literature with EVC syndrome complicated with hepatic failure and renal failure requiring respectively liver transplantation [13] and renal transplantation [12] in childhood age.

EVC syndrome is an autosomal recessive disorder, with a Mendelian risk of 25\% for subsequent pregnancies. Prenatal abnormalities may be early discovered by ultrasound examination, after the $18^{\text {th }}$ gestation week; they include narrow thorax, marked shortening of the long bones, hexadactyly of hands and feet, and cardiac defect $[11,12]$ leading to discussing the diagnosis of short rib-polydactyly syndromes. Increased first-trimester fetal nuchal translucency thickness in association with ECV has been described at $13^{\text {th }}$ week of gestation [14]. Fetal echocardiography is used to reveal fetal cardiac pathologies.

Molecular genetic testing by amniocentesis or chorion villi biopsy, using linked microsatellite markers flanking the EVC locus, provided the linked markers have been established in the family with a previously affected sibling. Prenatal diagnosis using molecular genetic techniques is possible on DNA extracted from chorionic villus samples $[14,15]$. Since EVC syndrome is a multi-systemic disorder it can be managed by a multidisciplinary team of physicians including clinical geneticist, cardiologist, pulmonologist, orthopedist, urologist, physical and occupational therapist, dentist, psychologist, developmental pediatrician (if developmental delay is present), pediatric neurologist (if developmental delay is present) and we would add the nephrologists for the cases complicated with renal failure. Although is known that renal structural or tubular abnormalities are rare in EVC syndrome it should be stressed that early detection of such abnormalities is essential for better management and prevention of further renal damage and development of hypertension and renal failure. The significance of monitoring should be also stressed with early ultrasound to detect structural abnormalities and regular urineanalysis and urine for amino acides to assess general tubular function.

\section{Conclusion}

We think that this case is the first described in the literature with EVC syndrome survived till the adult age who has developed renal failure and requiring a renal transplantation. All specialists involved in the care of an individual with EVC syndrome should have an understanding of the disease, its broad and varied manifestations, and challenges, including the psychological and emotional impact of this disease. It would be interesting to perform the genetic analysis in this family in order to stablish genetic- phenotipic correlation.

\section{References}

1. Ellis RWB, van Creveld S. A syndrome characterized by ectodermal dysplasia, polydactyly, chondrodysplasia, and congenital morbus cordis: report of three cases. Arch Dis Child. 1940;5:65

2. Ruiz-Perez VL, Ide SE, Strom TM, Lorenz B, Wilson D, Woods K, King L, Francomano C, Freisinger P, Spranger S, Marino B, Dallapiccola B, Wright $\mathrm{M}$, Meitinger T, Polymeropoulos $\mathrm{MH}$, Goodship J. Mutations in a new gene in Ellis-van Creveld syndrome and Weyers acrodental dysostosis. Nat Genet. 2000; 24:283-286.

3. Mac Kusick V. Ellis-van Crefeld syndrome and the Amish. Nature Genet. 2000;24:203-204.

4. Al-Gazali L, Bakir M, Hamid Z, Varady E, Varghes M, Haas D, Bener A, Padmanabhan R, Abdulrrazzzaq YM, Dawodu AK. Birth prevalence and pattern of osteochondrodysplasias in an inbred high risk population. Birth Defects Res Part A Clin Mol Teratol. 2003;67:125-132.

5. Polymeropoulos M, Ide S, Wright M, Goodship J, Weissenbach J, Pyeritz R, Da Silva E, Ortiz De Luna R, Francomano CA. The gene for the Ellis-van Creveld syndrome is located on chromosome 4p16. Genomics. 1996;35:1-5.

6. Tompson SW, Ruiz-Perez VL, Blair HJ, Barton S, Navarro V, Robson JL, Wright MJ, Goodship JA. Sequencing EVC and EVC2 identifies mutations in two-thirds of Ellis-van Creveld syndrome patients. Hum Genet. 2007;120:663-670.

7. Blackburn MG, Belliveau RE. Ellis-van Creveld syndrome. A report of previously undescribed anomalies in two siblings. Am J Dis Child. 1971; 122(3):267-270.

8. Baujat G, Le Merrer M. Ellis-Van Creveld syndrome. Orphanet J Rare Dis. 2007;2:27

9. Weiss $\mathrm{H}$, Crosert $\mathrm{AD}$ Jr.Chondroectodermal dysplasia:Report and review of literature. J Pediatrics. 1995;46:268-75. 
10. Horigome $\mathrm{H}$, Hamada $\mathrm{H}$, Sohda $\mathrm{S}$, Oyake $\mathrm{Y}$, Kurosaki $\mathrm{Y}$ Prenatal ultrasonic diagnosis of a case of Ellis-van Creveld syndrome with a single atrium. Pediatr Radiol. 1997;27:942944.

11. Böhm N, Fukuda M, Staudt R, Helwig H. Chondroectodermal dysplasia (Ellis-van Creveld syndrome) with dysplasia of renal medulla and bile ducts. Histopathology. 2007;2(4):267-281.

12. Moudgil A, Bagga A, Kamil ES, Rimoin DL, Lachman RS, Cohen AH, Jordan SC. Nephronophthisis associated with Ellisvan Creveld syndrome. Pediatr Nephrol. 1998;12(1):20-22.

13. Black D, Reutter J, Johnson M, Fair J, Woosley J, Gerber D. Liver transplantation in Ellis-van Creveld syndrome: A case report. Pediatr Transplant. 2002;6(3):255-259.

14. Guschmann M, Horn D, Gasiorek-Wiens A, Urban M, Kunze J, Vogel M. Ellis-van Creveld syndrome: examination at 15 weeks' gestation. Prenatal Diagnosis. 1999;19(9):879-883.

15. Peraita-Ezcurra M, et al. Gene. Ellis-van Creveld syndrome in a fetus with rhizomelia and polydactyly. Report of a case diagnosed by genetic analysis, and correlation with pathological and radiologic findings. 2012; 10;499(1):223-225. 